\title{
A Multicentre Based Observation of a Screening tool to Differentiate Microcytosis and Hypochromia
}

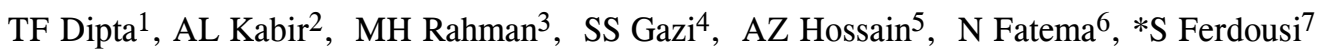 \\ ${ }^{1}$ Dr. Tashmim Farhana Dipta, Associate Professor, Transfusion Medicine and Haematology, BIRDEM General \\ Hospital and Ibrahim Medical College, \\ ${ }^{2}$ Dr. Amin Lutful Kabir, Associate Professor, Department of Haematology, Bangabandhu Sheikh Mujib Medical \\ University, Shahbagh, Dhaka \\ ${ }^{3}$ Dr. Md. Hafizur Rahman, Incharge, Haematology unit, ICDDRB, Mohakhali, Dhaka \\ ${ }^{4}$ Dr. Gazi Sharmin Sultana, Consultant, General Laboratory (Department of Clinical Pathology, Clinical \\ Biochemistry and Haematology), BIRDEM General Hospital, Shahbag, Dhaka \\ ${ }^{5}$ Dr. Ahmed Zahid Hossain, Consultant, Department of Paediatric Surgery and Incharge of Emergency, Square \\ Hospitals Ltd, Panthapath, Dhaka, \\ ${ }^{6}$ Dr. Nafisa Fatema, Resident Medical officer, Department of Paediatrics, Institute of Child Health and Shishu \\ Hospital, Sher-E Bangla Nagar, Dhaka \\ 7*Prof. Dr. Shamima Ferdousi, Associate professor and Head, Department of Pathology, Ibrahim Medical \\ College, Shahbag, Dhaka \\ *Corresponding Author
}

Date of submission: 07 April 2015

Date of acceptance: 10 May 2015

\begin{abstract}
Back ground: Iron deficiency anemia (IDA) and beta-thalassaemia trait (B-TT) are the most common causes of hypochromic microcytic anemia. Many indices have been defined to quickly discriminate these similar entities via parameters obtained from automated blood count analyzers.

Methodology: The purpose of the study was to evaluate the predictive value of these indices in differential diagnosis of IDA and B-TT in adult cases. In this study we use auto-analyzer based formula of percentages of microcytic and hypochromic red cells $(\mathrm{M} / \mathrm{H}$ ratio $=\%$ of Microcytosis/\% of Hypochromia) as a screening tool for thalassaemia trait in Bangladeshi population.

Results: A total of 150 subjects w ere included in this study with 50 known obligate carrier of beta-thalassaemia trait and 100 patients with hypochromia and microcytosis. Confirmatory tests for IDA were performed if serum ferritin level was $<12 \mathrm{ng} / \mathrm{ml}$ and confirmatory test for Beta-thalassaemia trait (BTT) and Haemoglobin E trait can be considered when $\mathrm{HbA}_{2}>3.5 \%$, on agarose gel Haemoglobin electrophoresis at an alkaline $\mathrm{pH}$ (8.6) where, in addition, $\mathrm{MCV}<76 \mathrm{fl}$ and/or MCH $<27 \mathrm{pg}$. BTT was selected with $\mathrm{HbA}_{2}>3.5 \%$, while the non- BTT group were those with $\mathrm{HbA}_{2}<3.5 \%$. The final analysis of the result revealed that $\mathrm{M} / \mathrm{H}$ ratio is a very sensitive index for betathalassaemia trait. In our study, the sensitivity, predictive value and diagnostic accuracy of the $\mathrm{M} / \mathrm{H}$ ratio for the beta thalassaemia trait were $96 \%, 90.4 \%$ and $90.4 \%$ respectively and also identify all cases of coexistent iron deficiency.
\end{abstract}

Conclusion: Thus $\mathrm{M} / \mathrm{H}$ ratio is an easy, reliable and sensitive index which can be used for mass screening of betathalassaemia trait, particularly in a population where iron deficiency anemia is also prevalent.

Key Words: M/H ratio, thalassaemia trait

\section{Introduction}

It has been estimated that $20 \%$ of the world's population is iron deficient. Iron deficiency anemia is the most common type of anaemia throughout the world and dietary deficiency is the commonest cause $^{1}$. Whereas, thalassaemia which is a

commonest inherited gene disorder is prevalent worldwide $^{1,2}$. Bangladesh is situated in the thalassaemia belt and Beta-thalassaemia is common here ${ }^{2,3}$. There are a significant number of patients who have concurrent iron deficiency and beta- 
thalassaemia trait \& other haemoglobinopathies ${ }^{4,5}$. World Health Organization (WHO) estimates that at least $6.5 \%$ of the world populations are carriers of different inherited disorders of Haemoglobin. A conservative World Health Organization (WHO) report showed about $3.0 \%$ of populations are carriers of Beta thalassaemia and $4.0 \%$ are carriers of Hb-E in Bangladesh, which means that there are about 3.6 millions carriers of beta thalassaemia and 4.8 millions carriers of $\mathrm{Hb}-\mathrm{E}$ and affected birth per thousand of Beta thalassaemia is $0.106 \& 0.300$ of $\mathrm{Hb}-\mathrm{E} /$ Beta thalassaemia. It is presumed that approximately six thousand thalassaemic children are born each year in Bangladesh ${ }^{6,7}$. Several screening procedures have been devised but these are neither cost effective nor sensitive enough ${ }^{8-11}$. A simple procedure utilizing cell counter introduced recently, for discrimination of beta-thalassaemia trait from iron deficiency anemia, is the ratio between percentage of microcytic and hypochromic red cells $(\mathrm{M} / \mathrm{H} \text { ratio })^{10-12}$. The quantification of the percentages of microcytic and hypochromic erythrocytes has proved clinically useful in the differential diagnosis between thalassaemic and nonthalassaemic microcytosis ${ }^{12}$. Iron-deficient erythropoiesis is characterized by the production of RBC with a decreased haemoglobin concentration and high hypochromic cells percentage, while microcytes of beta thalassaemia are generally smaller with low haemoglobin content but more preserved haemoglobin concentration. The percentage of hypochromic cells, defined as RBC with low haemoglobin concentration, tends to be higher in patients with IDA than in thalassaemia carriers, while the percentage of microcytes, increased in thalassaemia carriers, shows the opposite trend; the quotient \% Micro/\% Hypo, M/H ratio amplifies the difference between the two groups ${ }^{10,12,17}$. However, the reason for the discrepancies among the various studies may be also due to the different sample size and the inclusion of patients with severe and mixed cases of thalassaemia and iron deficiency anaemia. Many formulae, based on haemoglobin, RBC count, MCV and RDW are useful to discriminate between these two common causes of microcytic hypochromic anaemia in uncomplicated cases, but in patients who have both IDA and BTT, a situation common in Indian subcontinent, needs a special consideration ${ }^{4}$. In our population there is a high prevalence of iron, vitamin $B_{12}$ and folic acid deficiencies along with high incidence of BTT which affects the RBC indices, so we may also have a large number of atypical cases with concomitant diseases ${ }^{1}$. Objective of our study was to evaluate and quantification of the $\%$ microcytic and \% hypochromic ratio index (M/H ratio), which was calculated from RBC parameters, using fully automated haematology cellcounter to observe this ratio as a tool to evaluate clinical usefulness in the differential diagnosis between thalassaemic and non-thalassaemic microcytosis.

\section{Materials \& Methods}

The material comprised of 150 subjects referred to the Department of Pathology, Institute of Child Health and Shishu Hospital, Sher-E Bangla Nagar, Dhaka, Department of Transfusion Medicine and Haematology section of Department of Clinical Pathology, Clinical Biochemistry and Haematology, BIRDEM General Hospital, Dhaka and Department of Haematology, BSMMU, Dhaka from $1^{\text {st }}$ January 2003 to $3^{1 \text { st }}$ December, 2005, for complete blood counts (CBC) for the various reasons. They comprised of both sexes, all ages with children above 12 years. The total 150 subjects were divided into two groups. Group I comprised of 50 subjects of known obligate carrier of beta-thalassaemia trait diagnosed by $\mathrm{HbA}_{2}$ (also by family studies if necessary). Serum ferritin was within the normal limits in all of them. Estimation of $\mathrm{M} / \mathrm{H}$ ratio, repeat haemoglobin electrophoresis, serum ferritin level and NESTROF $_{12}$ (Naked Eye Single Tube Red Cell Osmotic Fragility) were also done. The age of Group I ranged from 18 to 55 years (median 24 years) and male to female ratio was $1.5: 1$. On the other hand, Group II was composed of 100 patients with hypochromia and microcytosis diagnosed by cell counter, peripheral blood film, haemoglobin electrophoresis and serum ferritin level. This Group II was further divided into four groups by the observation of $\mathrm{HbA} 2$ and serum ferritin level. The age of Group II subjects ranged from 12-60 years (median 35 years) and male to female ratio of $1.3: 1$. The parents of $56 \%$ were first cousins and of $11 \%$ were related but not first cousins. The parents of $33 \%$ had no previous relationship. $\mathrm{M} / \mathrm{H}$ ratios were calculated from the 
blood samples with the help of the autoanalyzer using the calculation below. Study of peripheral blood film after properly staining with Giemsa stain was observed. Hypochromia was defined as central pallor more than $1 / 3^{\text {rd }}$ in a $\mathrm{RBC}$, where the visible field showed no overlapping and even distribution of RBC. This \% Microcytosis / \% Hypochromia haematological parameters were obtained from cell counter (fully automated haematology auto-analyzer Advia, USA and Sysmex, Japan). All individuals were subjected to detailed interview, adequate counseling and thorough clinical examination. About 5 to $6 \mathrm{ml}$ o venous blood was collected from each of the subject from both study and control groups through a clean vene-puncture and distributed in the following manner:

1. $1.5 \mathrm{ml}$ blood was properly mixed with potassium EDTA to a final concentration of 2.0 $\mathrm{mg} / \mathrm{ml}$ and used for blood count by haematology auto-analyzer and a peripheral blood film was also made.

2. $1.5 \mathrm{ml}$ blood was properly mixed with potassium EDTA to a final concentration of 2.0 $\mathrm{mg} / \mathrm{ml}$ and used for preparation of haemolysate for Haemoglobin electrophoresis and estimation of $\mathrm{HbA}_{2}$.

Rest of the blood was transferred into a clean glass test tube and allowed to clot. Clear serum was separated into a clean test tube and preserved for estimation of serum ferritin. In our study, M/H ratio has been calculated as:

$\mathrm{M} / \mathrm{H}$ ratio $=\%$ of Microcytosis / \% of Hypochromia ${ }^{12-13,15}$.

Finally, sensitivity \& specificity, and positive \& negative predictive values were calculated as follows:

Sensitivity: True positive / (true positive + false negative)

Specificity: True negative / (true negative + false positive)

Positive predictive value: True positive / (true positive + false positive)

Negative predictive value: True negative/ (true negative + false negative) and

Youden's index $14=[($ sensitivity + specificity $) \mathrm{x}$ 100] - 100.
Here, Youden's index takes into account both sensitivity and specificity and gives an appropriate measure of validity of particular technique. Serum ferritin estimation was performed by Radioimmuno assay (RIA) technique. Calibration was performed by using standards of $0-1000 \mathrm{ng} / \mathrm{ml}$. Quality control was also performed within assay and between assays running of controls. The sensitivity, predictive value and diagnostic accuracy of $\mathrm{M} / \mathrm{H}$ ratio for Beta-thalassaemia trait was calculated according to the method of Galen and Gambino ${ }^{1-3}, 10-17$.

\section{Results}

This was a cross sectional analytic study, although we use Group I and Group II, the results were seen in an observatory manner and Group II was divided into four groups by the observation of HbA2 and serum ferritin level. The results of various haematological parameters and diagnostic tests of the Group I and the Group II with hypochromia and microcytosis are presented in table-I. The sensitivity of the $\mathrm{M} / \mathrm{H}$ ratio of Betathalassaemia trait was calculated to be $96 \%$ from the above calculation. Table -II showed, on the basis of HbA2 and serum ferritin level study subject $(n=100)$ were divided into four groups: Beta-thalassaemia trait (BTT) was $67 \%$, Betathalassaemia trait with iron deficiency (BTT with IDA) in $18 \%$, iron deficiency anaemia in $9 \%$ and miscellaneous / unclassified in $6 \%$. The $\mathrm{M} / \mathrm{H}$ ratios have been implemented to correctly identify all the cases of BTT and BTT with IDA. There were 9 false positive which actually belonged to IDA category. The sensitivity and predictive value of $\mathrm{M} / \mathrm{H}$ ratio for BTT was $96 \%$ and $90.4 \%$ respectively found from the above calculation. The diagnostic accuracy was $90.4 \%$ using this calculation. Six cases belonged to the miscellaneous (unclassified group) with normal levels $\mathrm{HbA} 2$ and serum ferritin. These case could be of beta-thalassaemia trait, -thalassaemia or thalassaemia trait, but the exact cause could not be identified. 
Table-I: Haematological parameters and diagnostic tests of Group I (obligate carrier of betathalassaemia trait) and Group II (\% Hypocromic and $\%$ microcytic)

\begin{tabular}{lll}
\hline $\begin{array}{l}\text { Parameters \& } \\
\text { Diagnostic tests }\end{array}$ & $\begin{array}{l}\text { Group I } \\
(\mathbf{n}=\mathbf{5 0})\end{array}$ & $\begin{array}{c}\text { Group II } \\
(\mathbf{n}=\mathbf{1 0 0})\end{array}$ \\
\hline $\mathrm{Hb}(\mathrm{gm} / \mathrm{L})$ & $125 \pm 18.50$ & $113 \pm 2.35$ \\
$\mathrm{TRBC}\left(10^{12} / \mathrm{L}\right)$ & $5.8 \pm 1.80$ & $5.1 \pm 0.85$ \\
$\mathrm{MCV}(\mathrm{fl})$ & $65.3 \pm 4.30$ & $66.0 \pm 7.30$ \\
$\mathrm{MCH}(\mathrm{pg})$ & $20.0 \pm 1.50$ & $21.40 \pm 3.20$ \\
Serum ferritin (ng/ml) & $88.0 \pm 5.50$ & $85.6 \pm 4.80$ \\
$\mathrm{HbA}$ & $4.8 \pm 0.80$ & $3.7 \pm 0.80$ \\
\%Hypochromia & $17.6 \pm 12.0$ & $18.0 \pm 10.0$ \\
\%Microcytosis & $32.0 \pm 15.80$ & $27.5 \pm 14.80$
\end{tabular}

Table-II: On the basis $\mathrm{HBA}_{2}$ and serum ferritin level Group II $(n=100)$ were divided into four groups. All the Haematological parameters of these groups were shown in this table.

\begin{tabular}{lllll}
\hline $\begin{array}{l}\text { Parameters \& } \\
\text { Diagnostic } \\
\text { tests }\end{array}$ & $\begin{array}{l}\text { BTT } \\
(\mathbf{n}=67)\end{array}$ & $\begin{array}{c}\text { BTT + IDA } \\
(\mathbf{n}=\mathbf{1 8})\end{array}$ & $\begin{array}{l}\text { IDA } \\
(\mathbf{n}=\mathbf{0 9})\end{array}$ & $\begin{array}{c}\text { Misc. } \\
(\mathbf{n}=\mathbf{0 6})\end{array}$ \\
\hline $\mathrm{Hb}(\mathrm{gm} / \mathrm{L})$ & $11.70 \pm 1.45$ & $9.25 \pm 2.86$ & $7.90 \pm 1.48$ & $12.30 \pm 2.35$ \\
$\mathrm{RBC}\left(10^{12} / \mathrm{L}\right)$ & $5.10 \pm 0.90$ & $4.90 \pm 0.45$ & $4.10 \pm 0.50$ & $5.0 \pm 0.90$ \\
$\mathrm{MCV}(\mathrm{fl})$ & $66.5 \pm 3.90$ & $63.20 \pm 7.50$ & $66.0 \pm 4.35$ & $83.0 \pm 7.50$ \\
$\mathrm{MCH}(\mathrm{pg})$ & $22.0 \pm 2.40$ & $18.5 \pm 3.40$ & $20.8 \pm 2.90$ & $28.85 \pm 2.90$ \\
$\begin{array}{l}\mathrm{Serum} \text { Ferritin } \\
(\mathrm{ng} / \mathrm{ml})\end{array}$ & $117.0 \pm 10.90$ & $6.10 \pm 2.95$ & $2.60 \pm 3.90$ & $85.0 \pm 7.50$ \\
$\mathrm{HbA} 2$ & $5.10 \pm 0.90$ & $4.0 \pm 0.40$ & $2.25 \pm 0.60$ & $2.90 \pm 0.40$ \\
$\%$ Microcytosis & $28.60 \pm 16.80$ & $29.80 \pm 14.80$ & $28.10 \pm 6.60$ & $7.80 \pm 5.90$ \\
$\%$ Hypochromia $17.6 \pm 9.80$ & $19.20 \pm 12.60$ & $30.3 \pm 7.10$ & $8.40 \pm 5.90$
\end{tabular}

\section{Discussion}

There are only few studies reported previously on the $\mathrm{M} / \mathrm{H}$ ratio ${ }^{10-12}$. The reference ranges for the new RBC extended parameters and their values in anaemic patients with red cells abnormalities have been recently established ${ }^{5,17}$. Study showed, the \% Microcytosis was more increased in thalassaemia than IDA5. Study with the Advia series Siemens 2120 analyzer (Siemens Medical Solutions Diagnostics, Tarrytown, NY, USA) showed, that auto analyzer based $\mathrm{M} / \mathrm{H}$ ratio provided by this series has been proven to be a reliable index ${ }^{13,15}$. Mean $\%$ microcytosis was much more increased in thalassaemia $(36.5 \%)$ than in IDA $(28.8 \%$; -0.05$)$, while mean $\%$ hypochromic demonstrated an opposite trend (thalassaemia 3.4\%, IDA $20.4 \%$; p0.001) with Advia. On the other hand, mean $\mathrm{M} / \mathrm{H}$ ratio was higher in thalassaemia (15.1) than IDA (4.6; p-0.001). Here, the hypochromic red cells, measured by the Advia 2120 analyzer, defined by their $\mathrm{Hb}$ concentration ${ }^{13,15}$. In iron deficient erythropoiesis, synthesis of haemoglobin molecules are severely impaired leading to the production of RBC with low haemoglobin concentration19. Microcytes of beta-thalassaemia have small volume because of impaired globin synthesis, but almost normal Haemoglobin concentration. Only when these patients have an iron deficiency the percentage of hypochromic cells increases ${ }^{14,15}$. Although IDA and thalassaemia are both microcytic anemia, hypochromia and microcytosis exhibit opposite trends in both diseases. Iron deficient erythropoiesis is characterized by the production of RBCs with a decreased haemoglobin concentration and a high hypochromic cells percentage; while microcytes of beta thalassaemia are generally smaller, with more preserved haemoglobin concentration. In iron deficient erythropoiesis, synthesis of haemoglobin molecules is severely impaired leading to the production of RBCs with low haemoglobin concentration (hypochromic cells), whereas, beta thalassaemic patients have a high rate of microcytosis as a result of the chronic increase of erythropoiesis ${ }^{7}$. In addition, microcytes of beta thalassaemia have a small volume due to impaired globin synthesis, but almost normal haemoglobin concentration. According to a study, the Advia 2120 analyzer $\mathrm{M} / \mathrm{H}$ ratio index is reliable. This $\mathrm{M} / \mathrm{H}$ ratio ranked second, compared to the published indices evaluated, with a Youden index of $76.3 \%$ and a sensitivity of $99.2 \%$. According to the results of this study, an $\mathrm{MH}$ ratio value higher than 3.7 is a highly suspicious feature of beta thalassaemia, so $\mathrm{HbA}_{2}$ must be quantified to confirm the presence of the disease. Although the specificity is $77.1 \%$, due to its high sensitivity and less false negatives, when patients have a mild anemia and the differential diagnosis is more difficult, this $\mathrm{M} / \mathrm{H}$ ratio is a reliable index. Whereas, when using the Sysmex XE 5000 analyzer (Sysmex Corporation, Kobe, Japan), studies showed that the percentages of erythrocyte subsets can be calculated and the new parameters, such percentage of microcytic red cells (\% Micro 
$\mathrm{R}$ ), hypochromic red cells (\% Hypo $\mathrm{He}$ ) and percentage of macrocytic red cells ( $\%$ Macro R) can be obtained $13,14,17,18$. Red blood cells extended parameters including the microcytic (\% Micro R) and percentages of hypochromic red cells haemoglobin (\% Hypo He) reported by this analyzer revealed that, \% Micro $\mathrm{R}$ indicates the percentage of microcytic red cells with a volume $<60 \mathrm{fl}$ and $\%$ Hypochromia indicates the percentage of hypochromic red cells with a Haemoglobin content $<17 \mathrm{pg} 13$. There are also various red cell counter based formulae to differentiate BTT from IDA, e.g.: RDWI formula9 (MCV x RDW/RBC, where BTT $<220$ and IDA $>220$ ), Mentzer formula 4, 10 (MCV/RBC count) in which BTT $<13.0$ and in IDA $>$ 13.0.(Here, RBC: red blood cells; $\mathrm{Hb}$ : haemoglobin; MCV: mean cell volume; $\mathrm{MCH}$ : mean cell haemoglobin; RDW: red cell distribution width) ${ }^{9-17}$. Beside this $\mathrm{M} / \mathrm{H}$ ratio, Red blood cell count (RBC) is an index having both sensitivity and specificity more than $80 \%$ when, RBC value more than $5 \cdot 1012 / \mathrm{L}$ in favour of BTT and a value $<5 \cdot 1012 / \mathrm{L}$ in favour of IDA, as a powerful indices for adult cases. According to Demir, the Youden indices of RBC count and RDWI were the highest, viz, $82 \%$ and $80 \%$ respectively ${ }^{14}$. They concluded that RBC count and RDWI are the most reliable discrimination indices in differentiation between BTT and IDA; Mentzer, Ehsani's study showed the best discrimination index with sensitivity $89 \%$ and specificity of $81 \%$. Similar sensitivity $90.9 \%$ and specificity $80.3 \%$ were found by Ghafouri ${ }^{4,16,18}$. However, none of the indices allowed complete discrimination to distinguish BTT from IDA in a better way. None of the formulas are $100 \%$ sensitive and specific, therefore are of importance only for screening in areas of high prevalence of BTT1. Automated measurement of the red cells (RBC) microcytosis and hypochromia has proven clinical usefulness for the differential diagnosis. The present study was undertaken with the main objective of evaluating efficiency of $\mathrm{M} / \mathrm{H}$ ratios in screening for beta thalassaemia only, which is proved to be a reliable index according to the other studies ${ }^{10,12,13,17-21}$. Our MH ratio showed similarity to the published indices evaluated by Urrechaga $\mathrm{E}$ study, with a Youden index of 76.3\%13,17-21. The sensitivity, predictive value and diagnostic accuracy of this index for Beta-thalassaemia trait was found to be $96 \%, 90.4 \%$ and $90.4 \%$ respectively which almost match the results of study carried out by d'Onfrio: 100, 92.3, 93.3; Khattaak: 94.2, 84.4, 89.5 and M. Saleem: 100, 90.4 and 90.4 respectively $1,2,12-20$. Our \% Micro R/ \% Hypo He (MH ratio), similar to the index provided by Advia instruments and also similar with \%Micro R) \% Hypo He (M-H) by Sysmex XE 5000 analyzer where, new $\mathrm{M}-\mathrm{H}$ index proved to be a reliable index; a sensitivity of $98 \%$ ( $2 \%$ false negatives) and a specificity of $95.9 \%$ ( $4.1 \%$ false positives) are reached when a cut -off threshold of 11.5 is applied $^{13,21}$. M/H ratio also picked up all cases of Beta-thalassaemia trait with iron deficiency anaemia. Findings of our study indicate that $\mathrm{M} / \mathrm{H}$ ratio is specific and sensitive to be utilized as a population screening tool for detection of thalassaemia traits or carriers. It is superior to all so far described indices. There are only few studies reported previously on the $\mathrm{M} / \mathrm{H}$ ratio ${ }^{10-12}$. Moreover, cell counter-based formula has been used in the differential diagnosis of microcytic anemia ${ }^{10-20}$. The reference ranges for these new RBC extended parameters and their values in anaemic patients with red cells abnormalities have been recently established as a good indicator by showing the \% microcytosis was more increased in thalassaemia than $\operatorname{IDA}^{5,17}$.

\section{Conclusion}

Thalassaemia is an important health problem. Effort should be made to reduce the thalassaemic childbirth by developing a population screening programme. Our study showed that, automated cell counters provide a rapid, technically reliable method for screening of Beta-thalassaemia trait from concomitant Iron deficiency anaemia cases. M/H ratio is one of the good indices but required a specific haematology laboratory where auto-analyzer is also available. Haemoglobin electrophoresis and RIA/ELISA for the estimation of serum ferritin is also expensive and not available throughout the country and only a few centers and institutions have got these facilities. Mass awareness about the danger of thalassaemia, carrier detection and adequate counseling are the prerequisite to prevent silent spread. 


\section{Conflict of Interest}

The authors report no conflicts of interest.

\section{Acknowledgement}

We are grateful to all of our patients. We would also like to express our gratitude to all our departmental staff for their active involvement.

\section{References}

1. Saleem M. Hemoglobinopathies. Pak A F Med J, 1974; 25:9-16.

2. Saleem M, Mubarik P A. et al. Distribution pattern of haemoglobinpathies in northern areas of Pakistan. J Pak Med Assoc, 1985; 35: 106-109.

3. Khattak M F, Saleem M. Prevalence of Heterozygous Beta thalassaemia trait in Northern areas of Pakistan. J Pak Med Assoc, 1992; 42: 32-34.

4. Mentzer W C. differentiation of iron deficiency from Beta thalassaemia trait. Lancet, 1973; 882.

5. Lewis SM, Bain BJ, Bates I. Investigation of abnormal haemoglobins and thalassaemia. Dacie and Lewis Practical Haematology, London, Churchill Livingstone, 2006 Elsevier Ltd; Ed.10: 271-310.

6. World Health Organization. Management of birth defects and haemoglobin disorders: report of a joint WHOMarch of Dimes Meeting, Geneva, Switzerland, 17 - 19 May 2006. Reports by human genetics. Human genetics programme, WHO: 1-27.

7. DT Farhana, N Quamrun, C Subhagata. Pattern of haematological disorders in a tertiary diabetic hospital: a pilot study. J Bangladesh Coll Phys Surg, 2009; 27(3): 148-154.

8. Vichinsky EP. Changing patterns of thalassaemia worldwide. Ann N Y Acad Sci , 2005; 1054:18-24.

9. Mamtani M, Das K, Jawahirani A, Rughwani V, Kulkarni H. Is NESTROFT sufficient for mass screening for Betathalassaemia trait? J Med Screen, 2007; 14:169-173.

10. Nesa A, Munir SF, Sultana T, Rahman MQ, Ahmed AN. Role of discrimination indices in differentiation of beta thalassaemia trait and iron deficiency anaemia. Mymensingh Med J, 2011 Jan; 20 (1):110-4.

11. Beyan C, Kaptan K, Ifran A. Predictive value of discrimination indices in differential diagnosis of iron deficiency anemia and beta-thalassaemia. European Journal of Haematology, 2007; 78: 524-526.
12. Urrechaga E. Red blood cell microcytosis and hypochromia in the differential diagnosis of iron deficiency and b-thalassaemia trait. Int Jnl Lab Hem, 2009; 31: 528-534.

13. Urrechaga E, Borque L, Escanero JF. The role of automated measurement of red cell subpopulations on the Sysmex XE 5000 analyzer in the differential diagnosis of microcytic anemia. Int Jnl Lab Hem, 2011; 33: 30-36.

14. Demir A, Yarali N, Fisgin T, Duru F, Kara AR. Most reliable indices in differentiation between thalassaemia trait and iron deficiency anemia. Pedia Int, 2002: 44: 612-616.

15. Tassiopoulos $\mathrm{T}$, Konstantopoulos $\mathrm{K}$, Tassiopoulos $\mathrm{S}$, Rombos Y, Alevizou-Terzaki V, Kyriaki P. Erythropoietin levels and microcytosis in heterozygous beta-thalassemia. Acta Haematol, 1997; 98:147-149.

16. Ehsani MA, Shahgholi E, Rahiminejad MS, Seighali F, Rashidi A. A new index for discrimination between iron deficiency anemia and beta thalassemia minor: results in 284 patients. Pak J Bio Sci, 2009; 12; 473-475.

17. Tanaka C, Nagai T, Nakamura M, Yamauchi Y, Noguchi $\mathrm{K}$, Takimoto $\mathrm{Y}$, et al. Automated hematology analyzer $\mathrm{XE}$ 5000. Overview and basic performance. Sysmex J Int, 2007; 17 (Supp 3):1-6.

18. Ghafouri M, Motan S L, Sharifi S, Gohari LH, Attarchi Z. Comparison of cell counter indices in differentiation of beta thalassemia minor from iron deficiency anemia. Blood, 2006; 2 (sup 7): 385-389.

19. Brugnara C. Iron deficiency and erythropoiesis: new diagnostic approaches. Clin Chem, 2003; 49:1573-1578.

20. Rathod DA, Kaur A, Patel V, Patel K, Kabrawala R, Patel M, et al. Usefulness of cell counter based parameters \& formulas in detection of $\beta$ thalassaemia trait in areas of high prevalence. Am J Clin Pathol, 2007; 128: 585- 589.

21. Urrechaga E. Discriminant value of $\%$ Microcytic/\% Hypochromic ratio in the differential diagnosis of microcytic anemia. Clinical Chemistry and Laboratory Medicine2008: 46(12), 1752-1758. 